\title{
Slow slip events and strain accumulation in the Guerrero gap, Mexico
}

\author{
M. Radiguet, ${ }^{1}$ F. Cotton, ${ }^{1}$ M. Vergnolle, ${ }^{1,2}$ M. Campillo, ${ }^{1}$ A. Walpersdorf, ${ }^{1}$ N. Cotte, ${ }^{1}$ \\ and V. Kostoglodov ${ }^{3}$
}

Received 23 August 2011; revised 27 February 2012; accepted 29 February 2012; published 17 April 2012.

[1] Global positioning system (GPS) time series in Guerrero (Mexico) reveal the existence of large slow slip events (SSEs) at the boundary between the Cocos and North American plates. In this study, we examined the last three SSEs that occurred in 2001/2002, 2006 and 2009/2010, and their impact on the strain accumulation along the Guerrero subduction margin. GPS displacements were inverted to retrieve the slip distribution during each SSE and the inter-SSE coupling of the subduction interface. The three analyzed SSEs have equivalent moment magnitudes of between 7.50 and 7.65, their lateral extents are variable, and they all show significant slip in the Guerrero seismic gap. During the inter-SSE epochs, the interplate coupling is high in the area where slow slip subsequently occurs. In the Guerrero gap, the shallow portion of the plate interface from the trench to the coast is weakly coupled. The average slip deficit accumulated in the Guerrero gap over a period of 12 years, which corresponds to three cycles of SSE, is only $1 / 4$ of the slip deficit accumulated on both sides of the gap. Moreover, the regions of large slip deficit coincide with the rupture areas of recent large earthquakes. We conclude that the SSEs in the Guerrero gap release a significant part of the strain accumulated during the inter-SSE period. If large subduction thrust earthquakes occur in the Guerrero gap, their recurrence time is probably increased compared to adjacent regions.

Citation: Radiguet, M., F. Cotton, M. Vergnolle, M. Campillo, A. Walpersdorf, N. Cotte, and V. Kostoglodov (2012), Slow slip events and strain accumulation in the Guerrero gap, Mexico, J. Geophys. Res., 117, B04305, doi:10.1029/2011JB008801.

\section{Introduction}

[2] Convergence in subduction zone margins is accommodated through various processes that complement each other in space and time. At depths greater than about $40 \mathrm{~km}$, relatively continuous aseismic creep occurs, and at shallower depths, both seismic and aseismic slip can occur. Seismic slip in megathrust earthquakes generates the most damaging effects, but several forms of aseismic slip also occur in subduction zone margins, which account for a significant part of the elastic strain release. In the months to years following an earthquake, postseismic deformation complements the coseismic slip and accounts for a significant part of the total moment release [e.g., Heki et al., 1997; Hsu et al., 2006; Perfettini et al., 2010]. Transient aseismic slip that occurs without any apparent relationship to an earthquake has also been detected in several subduction zones [e.g., Schwartz and Rokosky, 2007], and this is referred to

\footnotetext{
${ }^{1}$ Institut des Sciences de la Terre, Université Joseph Fourier, CNRS, Grenoble, France.

${ }^{2}$ Now at Géoazur, Observatoire de la Côte d'Azur, CNRS, Université de Nice-Sophia Antipolis, Valbonne, France.

${ }^{3}$ Instituto de Geofísica, Universidad Autónoma de Mexico, Mexico City, Mexico.

Copyright 2012 by the American Geophysical Union. 0148-0227/12/2011JB008801
}

as silent earthquakes, or slow slip events (SSEs). SSEs have durations from days to years, and can occur periodically. To date, most studies have shown that the slip during SSEs occurs downdip of the so-called seismogenic section of the fault, in the transition zone between the stick-slip and steady slip. Nevertheless, a few studies have suggested that the slow slip can occur upward, in the shallow part of the subduction interface [e.g., LaBonte et al., 2009], or potentially intrudes into the assumed seismogenic zone [e.g., Sagiya, 2004; Kostoglodov et al., 2003; Larson et al., 2004]. The depth of SSEs can vary, however, depending on the width of the seismogenic zone [Wallace and Beavan, 2010]. Most of these results on the location of slow slip are still not very well constrained, and additional data are necessary to better resolve whether repeating SSEs and seismogenic zones are mutually exclusive on the plate interface. It is crucial to understand how seismic and aseismic slip complement each other in subduction zones. To achieve this, the precise location of slip during SSEs, and its relations with interseismic coupling and seismicity are of critical importance to evaluate the impact of SSEs on the settings of large subduction earthquakes.

[3] In the present study, we examined the SSEs that have occurred in the Guerrero gap, along the Pacific coast of Mexico, and their impact on the thrust earthquake potential of this region. The Guerrero seismic gap is a $\sim 200 \mathrm{~km}$ 


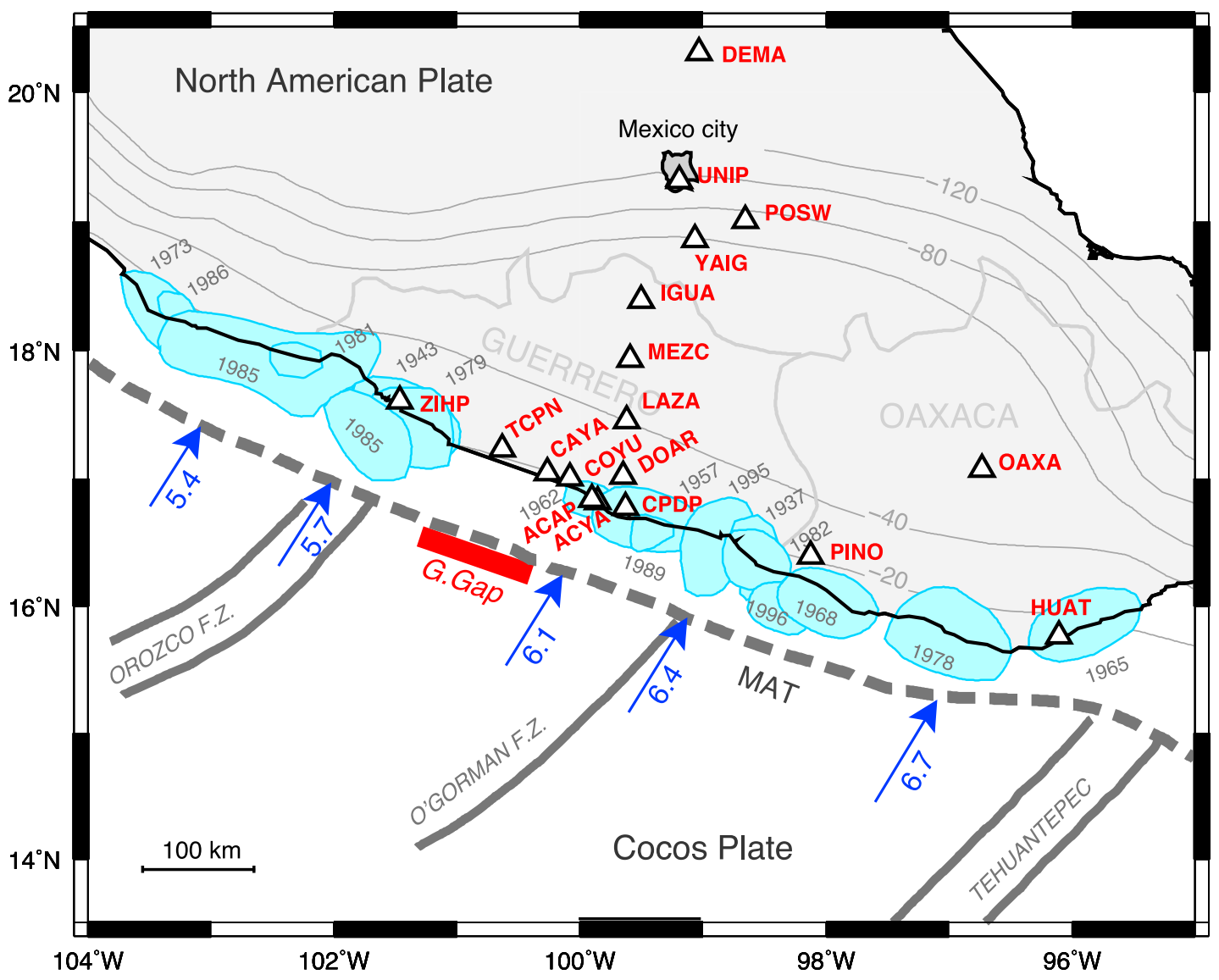

Figure 1. Seismotectonic map and GPS station locations (black triangles). Blue arrows, the direction and amplitude of the relative plate motions (in $\mathrm{cm} / \mathrm{yr}$ ) between the Cocos and North American plate [DeMets et al., 2010]. Cyan patches, major earthquakes rupture zones, with their years of occurrence. Thin gray lines, the isodepth contours (in $\mathrm{km}$ ) of the subducted oceanic slab (modified from Pardo and Suarez [1995] using the geometry proposed by Pérez-Campos et al. [2008]). Thick dashed gray line, Middle American Trench (MAT). Thick continuous gray lines, fracture zones. The location of the northwest Guerrero gap (G.Gap) is shown in red.

segment of the Cocos-North American plate boundary between $99.2^{\circ} \mathrm{W}$ and $101.2^{\circ} \mathrm{W}$. It can be divided into the northwestern Guerrero gap, with the presumed highest seismic potential [Kostoglodov et al., 1996], and the southeastern Guerrero gap, which coincides with the rupture of the 1957 and 1962 earthquakes [Ortiz et al., 2000]. No large subduction earthquake has occurred in the northwestern Guerrero gap since at least 1911 (with the location of the 1911 remaining uncertain [Figueroa, 1970; L. Rivera, personal communication, 2011]). This region has experienced only relatively small earthquakes since 1962. It has been estimated that if the entire gap ruptured in a single earthquake, it would reach a magnitude of $M_{w}$ 8.1-8.4 [Suárez et al., 1990]. Such an event would be devastating for nearby cities in the state of Guerrero, as well as for Mexico City. In this study, the term Guerrero gap, as shown in Figure 1, refers to the northwestern Guerrero gap (between $100^{\circ} \mathrm{W}$ and $\left.101.2^{\circ} \mathrm{W}\right)$.

[4] Continuous global positioning system (GPS) recordings in this region have revealed the occurrence of large SSEs, with an approximated recurrence period of 4 years [e.g., Cotte et al., 2009; Vergnolle et al., 2010]. The last three events occurred in 2001/2002, 2006 and 2009/2010, and they were recorded by nine or more continuous GPS stations. These SSEs produced surface displacements of up to $5-6 \mathrm{~cm}$. The estimated equivalent moment magnitudes were around 7.5 (see Kostoglodov et al. [2003], Larson et al. [2004], and Yoshioka et al. [2004] for the 2001/2002 SSE; Larson et al. [2007] and Radiguet et al. [2011] for the 2006 SSE; and Walpersdorf et al. [2011] for the 2009/2010 SSE). Several studies have also analyzed the inter-SSE GPS displacements [e.g., Yoshioka et al., 2004; Larson et al., 2004]. In the present study, we performed the first consistent modeling of all of the continuously observed SSEs (2001/ 2002, 2006, and 2009/2010), as well as the inter-SSEs displacements. These results are significant for two reasons: (1) they allows us to compare the characteristics of the slip for the last three SSEs; and (2) they allow us to evaluate the slip budget on the Guerrero gap since the 2001/2002 SSE, and thus to evaluate the impact of slow slip on the hazard level in this region over a period of $12 \mathrm{yr}$ (approximate time for three cycles of inter-SSE/SSE). Considering the uncertainties that exist for the geometry of the subduction interface in this region, we performed our analysis for two 
Table 1. GPS Stations Used in the Present Study ${ }^{\mathrm{a}}$

\begin{tabular}{ccc}
\hline Station Name & Date First Record & Date Last Record \\
\hline ACAP & $12 / 11 / 1998$ & $01 / 08 / 2010$ \\
ACYA & $11 / 01 / 2004$ & $06 / 10 / 2010$ \\
CAYA & $09 / 01 / 1997$ & $04 / 03 / 2011$ \\
COYU & $24 / 03 / 2003$ & $14 / 12 / 2010$ \\
CPDP & $30 / 05 / 2003$ & $21 / 03 / 2011$ \\
DEMA & $17 / 10 / 2003$ & $27 / 11 / 2008$ \\
DOAR & $22 / 03 / 2003$ & $12 / 01 / 2011$ \\
HUAT & $11 / 07 / 2000$ & $24 / 09 / 2010$ \\
IGUA & $06 / 06 / 2000$ & $01 / 03 / 2011$ \\
LAZA & $01 / 01 / 2007$ & $05 / 10 / 2010$ \\
MEZC & $09 / 09 / 2004$ & $31 / 01 / 2011$ \\
OAXA & $01 / 03 / 2001$ & $06 / 10 / 2010$ \\
PINO & $10 / 07 / 2000$ & $15 / 04 / 2010$ \\
POSW & $01 / 01 / 1997$ & $29 / 06 / 2003$ \\
TCPN & $19 / 07 / 2009$ & $23 / 11 / 2010$ \\
UNIP & $09 / 12 / 2005$ & $10 / 05 / 2011$ \\
YAIG & $03 / 03 / 1999$ & $10 / 05 / 2010$ \\
ZIHP & $07 / 07 / 2000$ & $22 / 01 / 2011$ \\
\hline
\end{tabular}

${ }^{a}$ The dates of first and last records are given for each station. Nine stations recorded the 2001/2002 SSE, 15 recorded the 2006 SSE and 16 recorded the 2009/2010 SSE (station TCPN did not record the beginning of the event). All of the stations are used the for inter-SSEs displacement estimations.

different plate interface models. We can thus test the sensitivity of our results with respect to the subduction geometry.

\section{Data and Methods}

\subsection{Processing of the GPS Data}

[5] Continuous GPS displacements are recorded by the Mexican permanent GPS networks that are maintained by the Universidad Nacional Autónoma de México (UNAM), with the Instituto de Geofisica (IGF) and the Servicio Sismológico Nacional (SSN). The number of GPS stations doubled between 2000 and 2010 (see Table 1 for details). In 2002, 9 GPS stations recorded the SSE in and around the Guerrero gap. In 2006 and 2009/2010, 15 and 16 GPS stations recorded the events, respectively. The stations are located mainly along the coast and on a transect perpendicular to the trench, between Acapulco and the north of Mexico city.

[6] The Mexican continuous GPS data, were complemented by data from global IGS (International GNSS Service) stations, and were processed following the commonly used approach of many tectonic studies over the past decade, to derive daily position time series with the GAMITGLOBK software (version 10.4) [Herring et al., 2006]. Particular emphasis was put on the use of up-to-date modeling of the environmental effects on the GPS measurements. We refer the reader to Vergnolle et al. [2010] and Walpersdorf et al. [2011] for a complete description of the data analysis procedure. The solution is expressed in the North American plate reference frame. The mean north, east and vertical weighted root mean squares averaged over all of the reference stations per component (from 30 to 60 reference stations distributed worldwide from 1997 to 2010, with an averaged of 52) are about 2.8, 3.2 and $11.4 \mathrm{~mm}$ respectively which attests that the reference frame realization is robust. The resulting 1997-2010 GPS position time series in Guerrero referenced to the fixed North American plate are shown in Figures 2, S1, and S2 for the north, east and vertical components, respectively. ${ }^{1}$

\subsection{Estimation of the Displacement Rate During Inter-SSE Periods and the Displacements During SSEs}

[7] During the periods between consecutive SSEs, the GPS time series show practically linear trends that correspond to constant strain rates. We evaluated the inter-SSE velocities for all of the inter-SSE periods (approximately 1998.5-2001.5, 2003-2006, 2007.5-2009) with respect to the North American plate reference frame. The precise dates used in the calculations vary from one station to the other because the SSE duration depends on the station location (from 5 to 15 months, depending on the SSE and on the station location [see Vergnolle et al., 2010; Walpersdorf et al., 2011]). For most stations, the displacement rates estimated over the different inter-SSE periods are very similar (within the 95\% confidence level; Figure S3). For a few stations, the differences are larger. This might have two origins: (1) it might reflect the existence of small transients [Vergnolle et al., 2010] and variations in the coupling ratio with time or (2) it might arise from different quality of the GPS data, which would result in less precise evaluations of the displacement rates. For each station and each component, the mean inter-SSE displacement rate is the weighted average of the inter-SSE displacement rates for all of the available time periods (see Figure S3 for the rates corresponding to each time period). The weighting corresponds to the amount of data available in each period. Hence, the periods with large data gaps are down-weighted with respect to the other periods in the evaluation of the mean rate. This mean inter-SSE displacement rate is shown as gray bars in Figure S3. This value is an approximation of a constant inter-SSE displacement rate, which averages out possible small transients. The associated errors are twice the standard deviations (2-sigmas) of the time series during the inter-SSE periods.

[8] In the present study, we considered three major SSEs that occurred in 2001-2002, 2006 and 2009-2010, and the possible small transients between these major events are averaged out in the evaluation of the inter-SSE velocities. The surface displacements during the SSEs were evaluated as the deviation from the linear inter-SSE loading. We thus removed the linear inter-SSE displacement rate from each time series, and then calculated the cumulative displacement for each SSE as the difference between the two successive zero-slope portion of the GPS time series (before and after each SSE). The errors associated with the displacements during the SSEs were calculated as the quadratic sum of the standard deviations (2-sigmas) of the zero-slope portion of the GPS time series before and after the SSE.

\subsection{Geometry of the Interface}

[9] The geometry of the subduction interface in Guerrero has been analyzed in many studies, which have used seismicity [Suárez et al., 1990; Singh and Pardo, 1993; Pardo and Suarez, 1995; Pacheco and Singh, 2010], seismicity and gravity [Kostoglodov et al., 1996], and more recently, receiver function analysis [Pérez-Campos et al., 2008; Kim et al., 2010]. All of these studies have shown that the

\footnotetext{
${ }^{1}$ Auxiliary materials are available in the HTML. doi:10.1029/ $2011 \mathrm{JB} 008801$.
} 

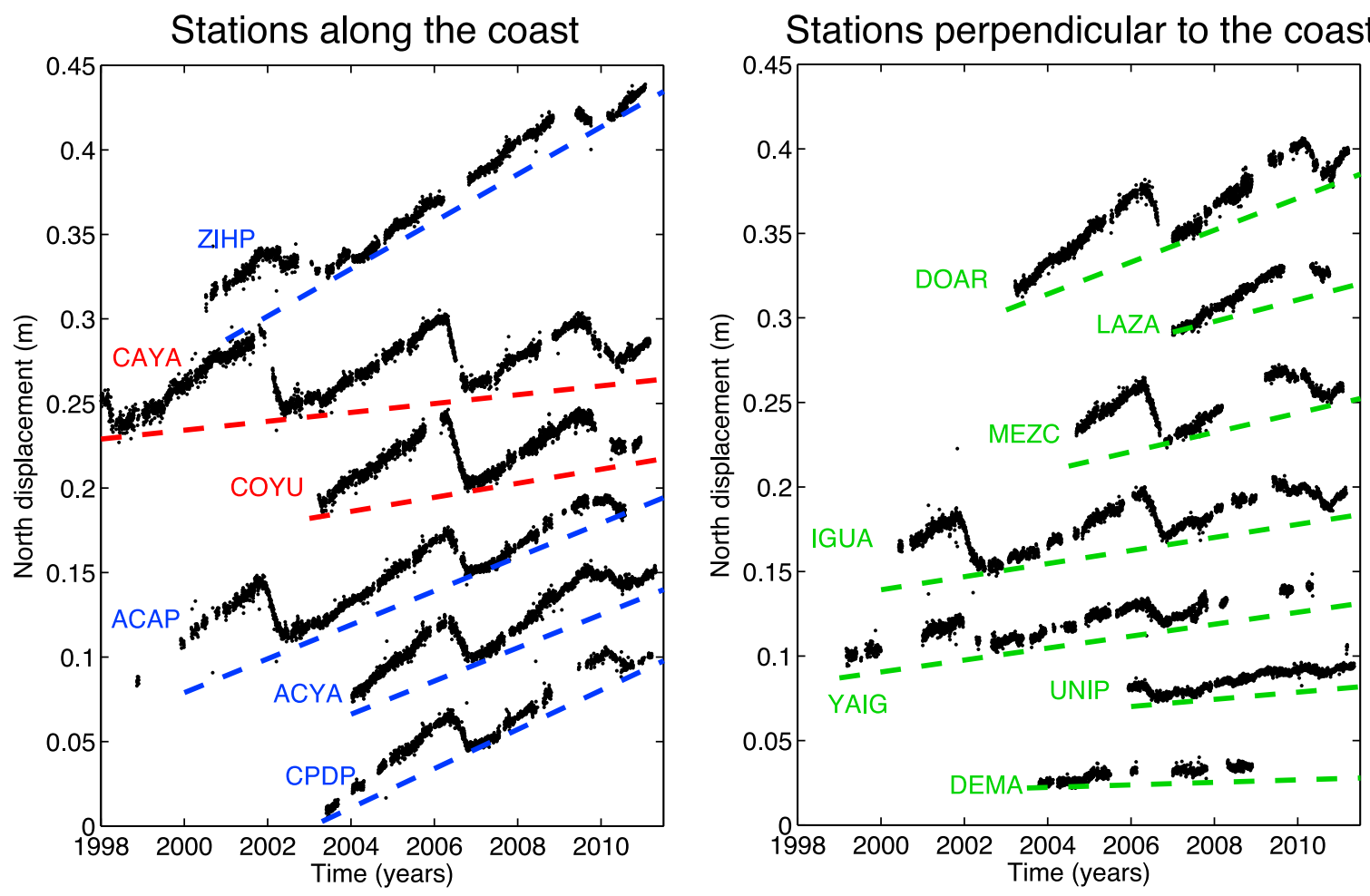

Figure 2. North position time series with respect to the North American plate reference frame for stations (left) along the coast and (right) perpendicular to the coast. Only stations located in the region of Guerrero are presented (stations POSW and TCPN are not shown because their time series are very short). Dashed lines, linear displacements predicted by the slip deficit model for $12 \mathrm{yr}$ presented in Figure 9. Colors depend on the station locations: red for coastal stations located into the gap, blue for coast stations located on the sides of the gap, and green for inland stations.

subduction interface is dipping at a shallow angle, and becomes subhorizontal at $100 \mathrm{~km}$ to $150 \mathrm{~km}$ from the trench. For the shallower portion of the slab, the estimated depth of the slab below the coast varies from $\sim 10 \mathrm{~km}$ to $\sim 25 \mathrm{~km}$.
The three principal geometries published and used in modeling are shown in Figure 3. Using one or another geometry for the modeling of slip during SSEs can lead to different conclusions about the updip slip limit, and bring confusion

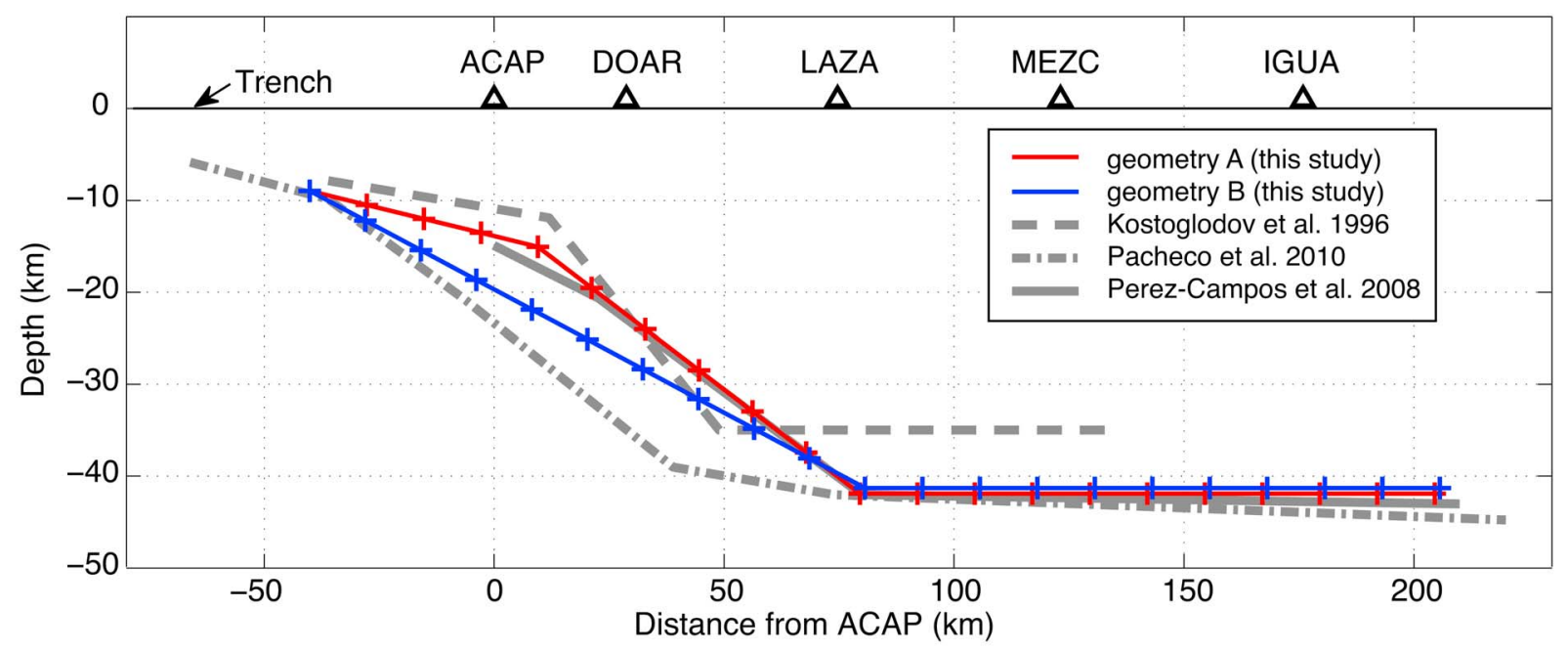

Figure 3. Geometries of the fault planes used in the present study, along a profile perpendicular to the trench (profile located below the line of inland GPS stations, from Acapulco (ACAP) to Mexico city). Red curves, geometry A; blue curve; geometry B; gray curves, principal geometries proposed in recent studies. Black triangles, GPS stations located on the profile. The distance from the GPS site ACAP to the Middle American Trench is $66 \mathrm{~km}$. Vertical exaggeration by a factor of 2 . 
to the debate as to whether or not the slow slip intrudes into the seismogenic zone in Guerrero. On this basis, we decided to test two different geometries, and to see whether or not our results are sensitive to the selected geometry (Figure 3).

[10] The receiver function profile [Pérez-Campos et al., 2008; Kim et al., 2010] is better able to resolve the geometry than the hypocenter location [Pacheco and Singh, 2010] $50 \mathrm{~km}$ to $150 \mathrm{~km}$ from the coast (i.e. the ACAP station, see Figure 3), because very few inter-plate earthquakes have been recorded in that region. Hence, our first criterion was to fit the characteristics of the flat slab from the receiver function studies. The two geometries are thus similar $80 \mathrm{~km}$ to $210 \mathrm{~km}$ from the coast. Important uncertainties remain for the geometry of the shallower portion of the interface. Depending on the dataset used to constrain this interface, as the hypocenter location alone [Pacheco and Singh, 2010] or when coupled to gravity data [Kostoglodov et al., 1996], the depth of the interface can vary from $10 \mathrm{~km}$ to $25 \mathrm{~km}$, below the coast in particular. We decided to fit both data sets as well as possible, considering our first constraint on the flat slab. Geometry A (Figure 3, red curve) is close to that of Kostoglodov et al. [1996], and is composed of three segments of varying dip angle. Geometry B (Figure 3, blue curve) is close to that of Pacheco and Singh [2010]. It is composed of only two segments, and thus reduces the potential biases in the modeling induced by a sudden change in the dip angle.

[11] The modeled subduction interfaces have the same extent along dip (perpendicular to the trench) of $250 \mathrm{~km}$. The extent along strike (parallel to the coast) varies from one SSE to another, and depends on the observed surface displacements in the southeast of the study area (see section 3 and Figure 3). The along strike extent of the modeled geometry is thus $468 \mathrm{~km}$ for the 2006 and 2009/2010 SSEs, and $542 \mathrm{~km}$ for the 2001-2002 SSE and the analysis of the inter-SSE coupling. The fault plane is divided into subfaults of dimensions $12.5 \mathrm{~km} \times 13 \mathrm{~km}$.

\subsection{Inversion Methods}

[12] The same inversion procedure was used to analyze each SSE and the inter-SSE displacement rates separately. The inversion scheme is similar to that of Radiguet et al. [2011]. For each SSE, all three components of the surface displacements $d$ were inverted to infer the slip distribution on the subduction interface $(m$, the vector of model parameters). For the inter-SSE period, the inter-SSE velocities (d) were inverted to find the slip deficit $m$ on the subduction interface (equivalent to the back-slip in the dislocation model [e.g., Savage, 1983]). The Green functions $G$ were calculated for a layered elastic half space, assuming the layered crustal model used by Hernandez et al. [2001]. Following the least-squares formulation of Tarantola [2005] for linear problems, the cost function $S(m)$ is:

$$
S(m)=\frac{1}{2}\left[(G m-d)^{t} C_{d}^{-1}(G m-d)+\left(m-m_{0}\right)^{t} C_{m}^{-1}\left(m-m_{0}\right)\right],
$$

and the model expectation $m$ is:

$$
m=m_{0}+C_{m} G^{t}\left(G C_{m} G^{t}+C_{d}\right)^{-1}\left(d-G m_{0}\right),
$$

where $m_{0}$ is the starting model, and $C_{d}$ is a diagonal matrix of the variances $\left(\sigma_{d}^{2}\right)$ of the data uncertainties. The a-priori model covariance matrix $C_{m}$ was used to introduce correlation between nearby parameters: i.e. for spatial smoothing. A decreasing exponential function [Radiguet et al., 2011] was used to introduce the correlation between nearby parameters. The correlation length, which defines the degree of smoothing, was selected using the best compromise between the slip roughness and a low misfit to the data (Figure S4). We selected the same correlation length of $50 \mathrm{~km}$ for all of the inversions. The inversions were performed for a fixed rake, avoiding any increase in the number of parameters to invert. For the inversion of each dataset, we selected the rake that produced the lowest misfit (see Figure S5). We, however, used the same rake for both geometries, so that the differences in the inversion results are only due to the geometries. The inversion rake of $90^{\circ}$ (pure thrust) is the most appropriate for the 2006 SSE modeling, a rake of $95^{\circ}$ for the 2001/2002 SSE, and a rake of $100^{\circ}$ for the 2009/2010 SSE and inter-SSE modelings. The pure thrust corresponds to surface displacements in the direction $22^{\circ} \mathrm{N}$, and the rake of $100^{\circ}$ to surface displacement in directions between $31.4^{\circ} \mathrm{N}$ and $32.1^{\circ} \mathrm{N}$ (depending on the dip angle of the subduction interface). These last directions are almost parallel to the direction of the plate convergence.

\section{Characteristics of the Last Three SSEs}

[13] Figure 4 shows the cumulative GPS displacements for each SSE. The 2001/2002 SSE generated the largest surface displacements $(6.6 \mathrm{~cm}$ of horizontal displacement at station CAYA). It also had the largest along-strike extent along the coast, as it affected station ZIHP in the western limit of the gap, as well as stations PINO and OAXA east of the gap (Figure 1). The 2006 SSE was limited to a smaller area; it did not affect stations ZIHP, PINO or OAXA, but produced GPS displacements almost as large as the 2001/2002 SSE in the gap region $(6.1 \mathrm{~cm}$ of horizontal displacement at CAYA). The 2009/2010 SSE produced smaller surface displacements in the gap area (only $4.3 \mathrm{~cm}$ at CAYA), but extended in the western limit of the gap, producing important displacement at station ZIHP.

[14] Inversion results (Figure 5) confirm these differences in lateral extent between the SSEs. The slip is always dominant in the Guerrero gap, with mean slip values from $7.7 \mathrm{~cm}$ to $9.4 \mathrm{~cm}$ (Table 2), although its lateral extent varies from one event to another. The equivalent moment magnitude is different for each SSE (see Table 2), which reflects changes in the lateral extent and the slip values. The slip distributions using geometry A or geometry B are very similar, although there are some small variations in the slip values (see Table 2).

[15] To better constrain the extent of slow slip towards the surface, we tested the up-dip limit of slow slip during each event by analyzing models in which the slip was suppressed in the upper part of the fault (Figure S6). Regardless of the geometry used, no slip is needed to fit the data in the first four lines of subfaults. The misfit starts to increase when the slip is suppressed in the fifth line, which corresponds to slip approximately below the coast. The depth at which the misfit becomes larger than two standard deviations varies 

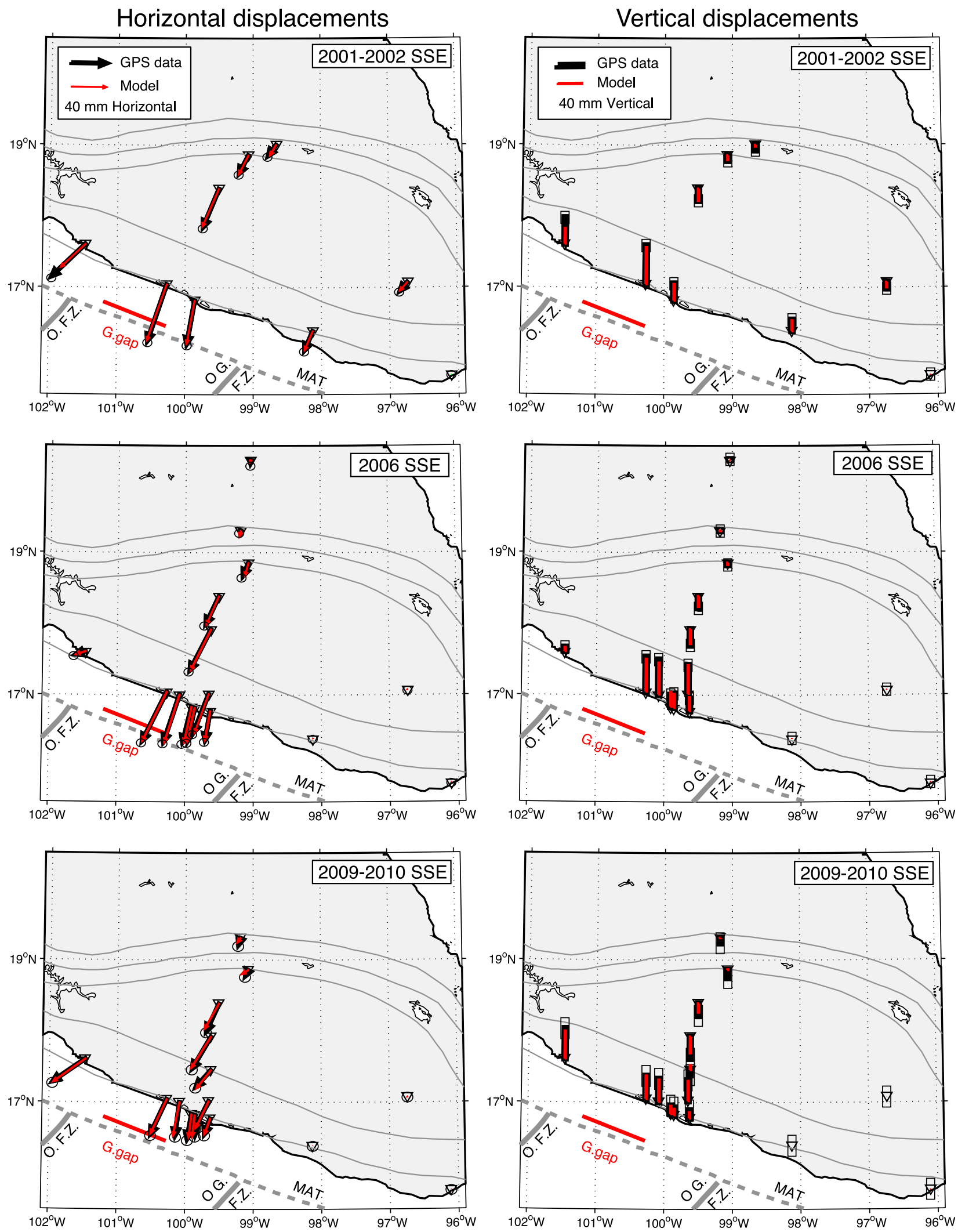

Figure 4. Vectors of the cumulative GPS displacements for each SSE.(left) Horizontal displacements. Black vectors, the data; red vectors, the model. (right) Vertical displacements. Thick black vertical bars, the data; red vertical bars, the model. Black circles and rectangles, errors at $95 \%$ confidence level. The modeled surface displacements correspond to the slip distributions shown in Figure 5 for the geometry B. Black triangles, GPS station locations. Thick dashed gray line, Middle American Trench (MAT). Thick continuous gray lines, fracture zones. The location of the northwest Guerrero gap (G.Gap) is shown in red. 
Geometry A
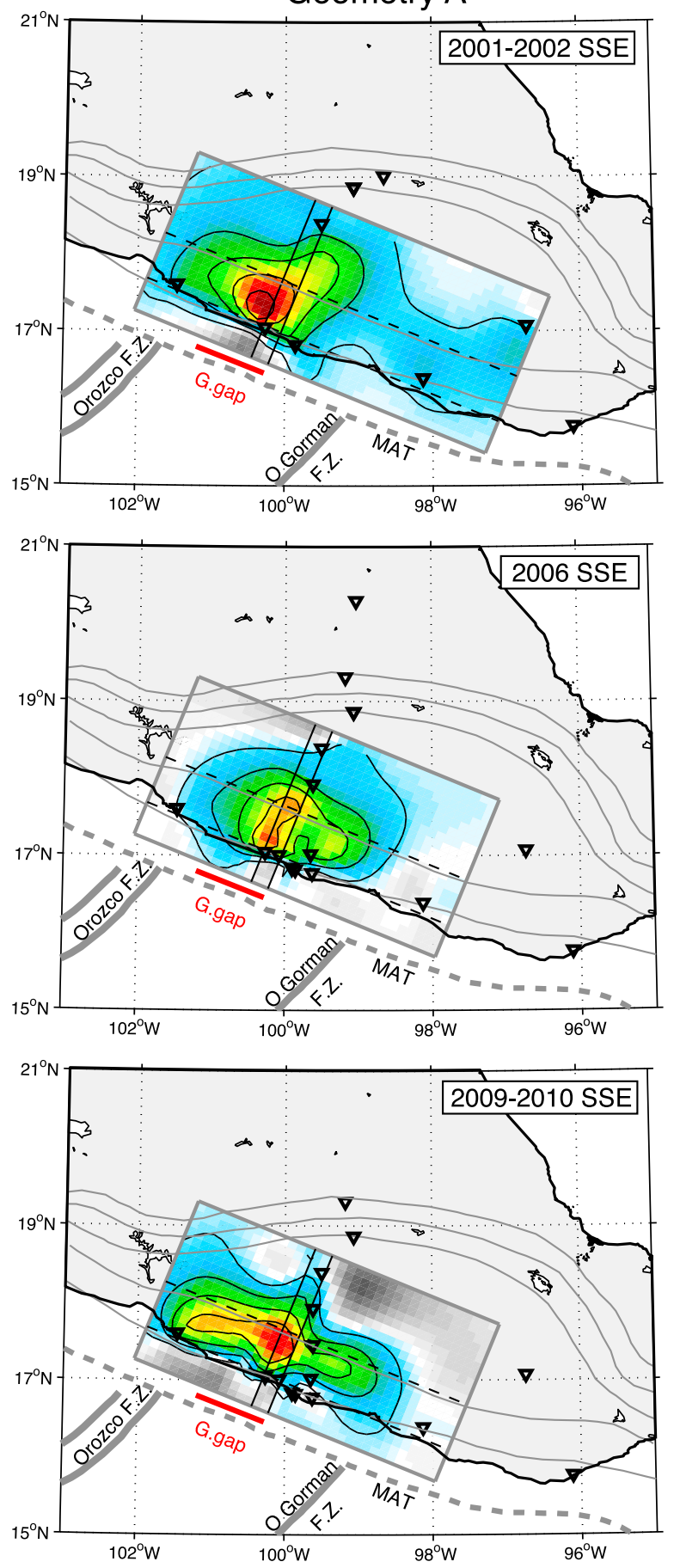

Geometry B
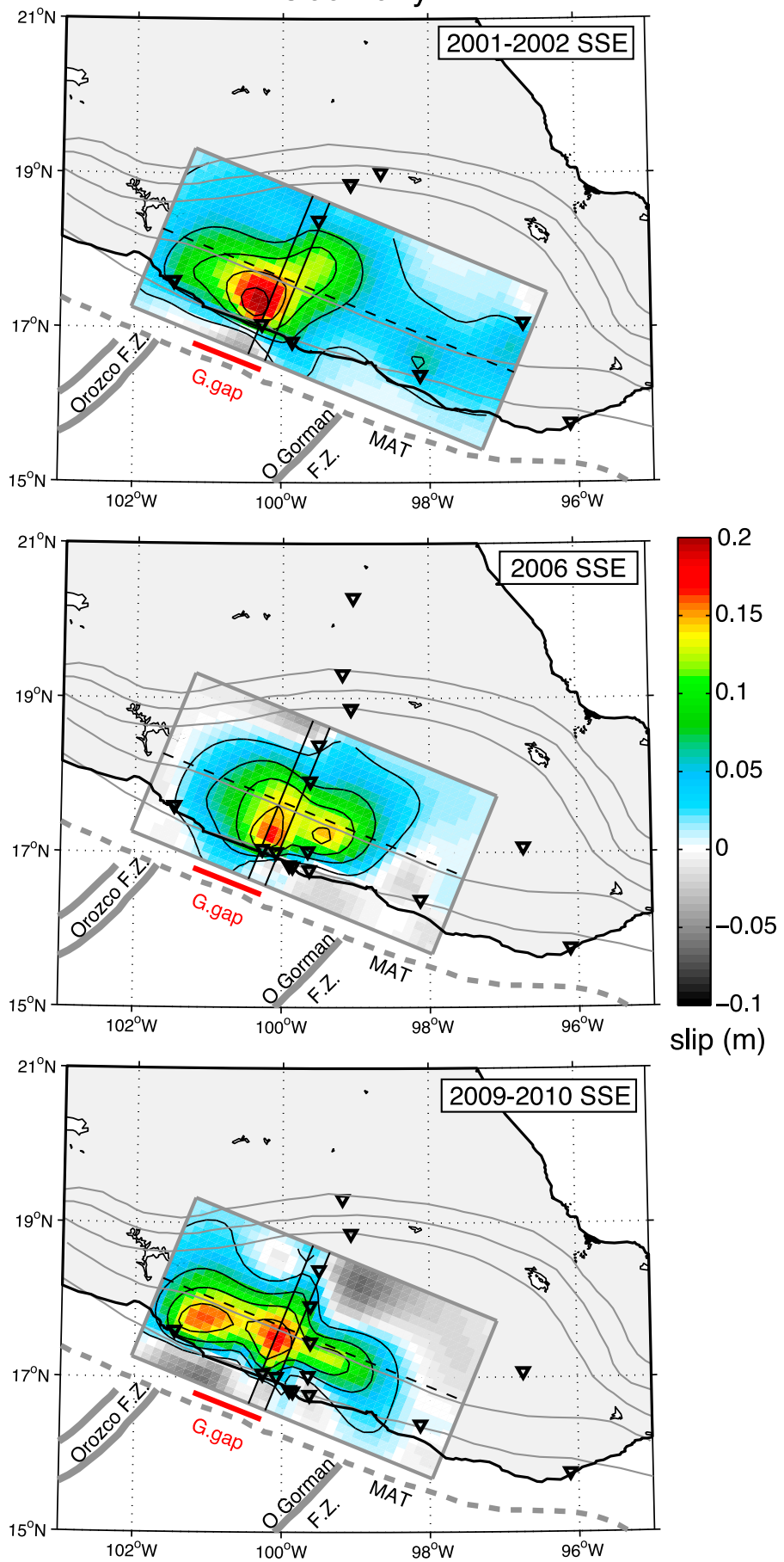

Figure 5. Slip distributions for the last three slow slip events: (top) 2001/2002, (middle) 2006, and (bottom) 2009/2010. (left) Geometry A. (right) Geometry B. The correlation length for each inversion is $\lambda=50 \mathrm{~km}$. Thin black lines, location of the cross-section in Figure 6. Thin dashed black lines, changes in the dip of the model subduction plane. The slip contour lines have $4 \mathrm{~cm}$ of slip spacing (from $2 \mathrm{~cm}$ to $18 \mathrm{~cm}$ ). Black triangles, GPS station locations. Thick dashed gray line, Middle American Trench (MAT). Thick continuous gray lines, fracture zones. The location of the northwest Guerrero gap (G.Gap) is shown in red.

from $\sim 20 \mathrm{~km}$ for geometry A, to $25 \mathrm{~km}-28 \mathrm{~km}$ for geometry B. A detailed analysis of the misfit for each individual stations is shown in Figure S7. The coastal GPS stations in the gap (Figure S7, red curves) are more sensitive to the updip slip limit than stations that border the gap (Figure S7, black and gray curves). The only exception is the high misfit at station ZIHP for the 2009/2010 SSE. These results suggest that shallower slip is required to fit the data in the 
Table 2. Characteristics of the Three Analyzed SSEs ${ }^{\mathrm{a}}$

\begin{tabular}{llllll}
\hline SSE Dates & \multicolumn{1}{c}{$M_{w}$} & $\begin{array}{c}\text { Mean Slip } \\
(\mathrm{cm})\end{array}$ & $\begin{array}{c}\text { Slip Area } \\
\left(10^{4} \mathrm{~km}^{2}\right)\end{array}$ & $\begin{array}{c}M_{w} \text { in the } \\
\text { Gap }\end{array}$ & $\begin{array}{c}\text { Mean Slip in } \\
\text { the Gap }(\mathrm{cm})\end{array}$ \\
\hline $2001 / 2002$ & $7.65(7.66)$ & 6.2 & $11.94(11.90)$ & 7.34 & $9.4(9.3)$ \\
2006 & $7.49(7.51)$ & 5.7 & $6.43(6.87)$ & $7.24(7.25)$ & $7.7(7.9)$ \\
$2009 / 2010$ & $7.53(7.54)$ & $6.3(6.4)$ & $6.66(6.55)$ & 7.24 & $9.2(8.6)$ \\
\hline
\end{tabular}

${ }^{a}$ Values in parentheses are for geometry B, if they are different from geometry A. A threshold of $1 \mathrm{~cm}$ of slip is considered for the calculation of the slip area and the mean slip.

Guerrero gap. This shallow slip in the gap area is constrained by the large vertical displacements at the stations CAYA and COYU (about twice as large as the displacements at stations ACAP, ACYA, and CPDP, see Figure 4), which cannot be fitted with the slip located too far inland (Figure S7). Station ZIHP recorded large vertical displacements during the 2009/ 2010 SSE which suggests that the slip was shallower for this event. These results show that the SSEs are quite shallow in the gap area, with an updip slip limit of around 15-20 km (considering the uncertainties for the slab location), and that the slow slip extending outside the gap occurs deeper.

[16] The downdip extend of the slow slip appears to extend further inland for the 2001/2002 than for the 2006 and 2009/ 2010 SSEs ( $\sim 200 \mathrm{vs} \sim 150 \mathrm{~km}$ from the coast, see Figure 6 ). This is probably just an artifact due to an increase in the resolution (Figure S8) through the installation of two new GPS stations between the coastal stations and station IGUA located $\sim 180 \mathrm{~km}$ inland. These stations (MEZC and LAZA, $\sim 125$ and $\sim 80 \mathrm{~km}$ from the coast, respectively) provide an additional constraint on the downdip slip extent, and show a downdip slip limit located $\sim 150 \mathrm{~km}$ inland from the coast, at a depth of $40 \mathrm{~km}$. To test the impact of the station density increase from 1998 to 2011 on the inversion results, we performed inversion for each SSE using only the data from the common stations (i.e. 8 stations). The slip distributions (Figure S9) obtained for the 2006 and 2009-2010 SSEs are smoother than those obtained using all of the available data. Moreover, the slip extends further towards the north, which is consistent with the lower constraint imposed one the north part of the fault plane (only one station versus two or three using all of the data available). Differences in the slip amplitude and location for the 3 SSEs are still visible using this homogeneous dataset.

[17] The comparison of the inversion results using geometries A and B reveals that the solution is very similar for these two geometries. For the two geometries tested, the slip is located at the same distance from the coast, although at different depths. In the Guerrero gap region, both geometries require slip at $10 \mathrm{~km}$ from the coast, which corresponds to depths of $15 \mathrm{~km}$ (geometry A) and $20 \mathrm{~km}$ (geometry B). We conclude that the shallow slow slip in the Guerrero gap area is a robust feature that does not depend on the geometry used. Considering all this, we only show the results using the simpler geometry B; the results for geometry A can be found in the auxiliary material (Figures S11 and S12).

\section{Inter-transient Coupling}

[18] The GPS displacements between the SSEs are inverted to infer the slip deficit on the subduction interface. This corresponds to the back-slip modeling approach proposed by Savage [1983]. The interplate coupling (here, the inter-SSE coupling) is the ratio of the slip deficit rate over the convergence rate. The convergence rate is obtained from the PVEL (Pacific VELocity estimates) model of DeMets et al. [2010]. This model is more accurate than the NUVEL-1A [DeMets et al., 1994] model, and in particular for the Cocos North America relative plate motion. In the study area, the differences in convergence direction and rate are about $3^{\circ}$ and $4 \mathrm{~mm} / \mathrm{yr}$, respectively. The convergence direction is $32^{\circ} \mathrm{N}$, which is similar to the rake selected for the inversion of inter-SSE displacements.

[19] Our modeling results for the inter-SSE displacements show that the coupling ratio is high $(>0.7)$ on the plate interface at a distance of $10 \mathrm{~km}$ to $90 \mathrm{~km}$ from the coast (see Figures 7 and 8). Further inland, in the flat portion of the slab, the coupling decreases. This decrease might be due to an increase in temperature [Manea et al., 2004]. The shallow,
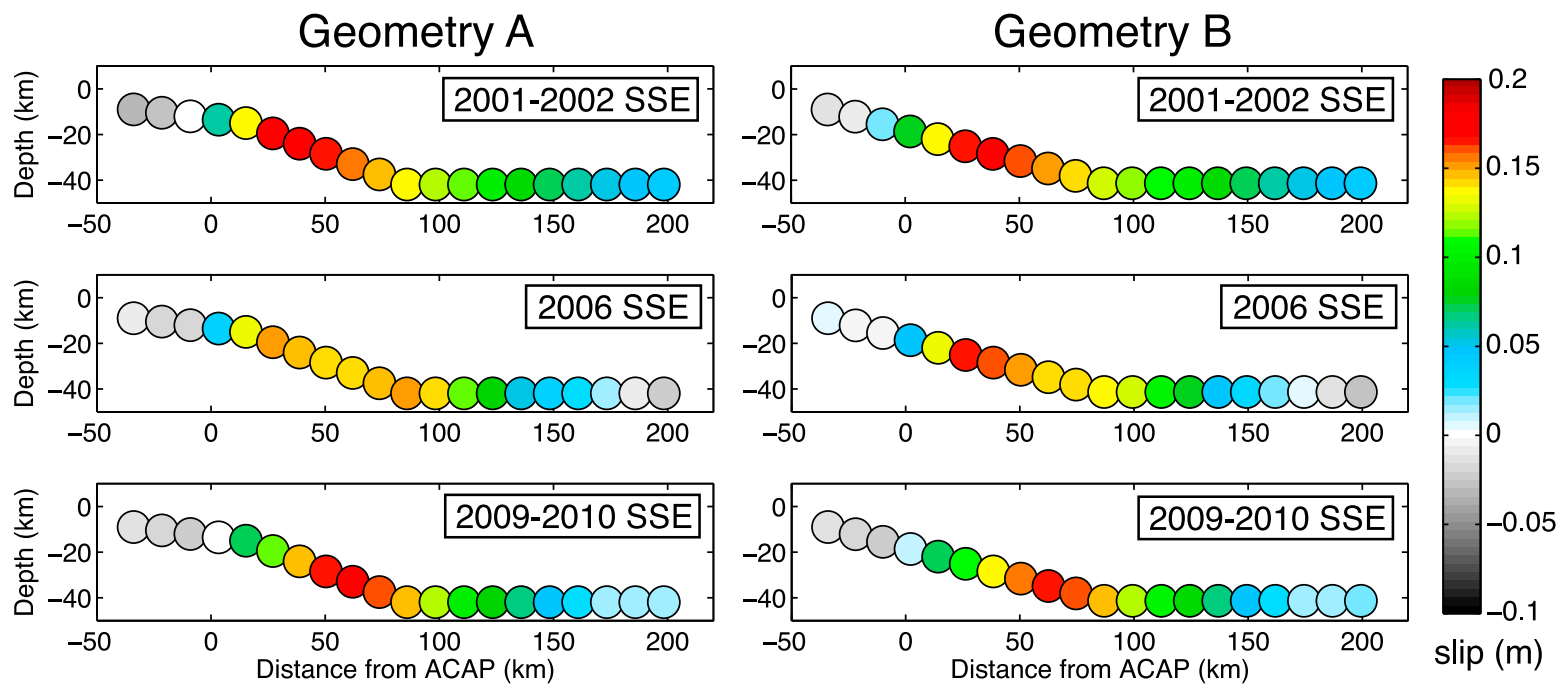

Figure 6. Cross-section of the slip distribution for the last three SSEs, located perpendicular to the trench in the Guerrero gap (see Figure 5). (left) Geometry A. (right) Geometry B. 


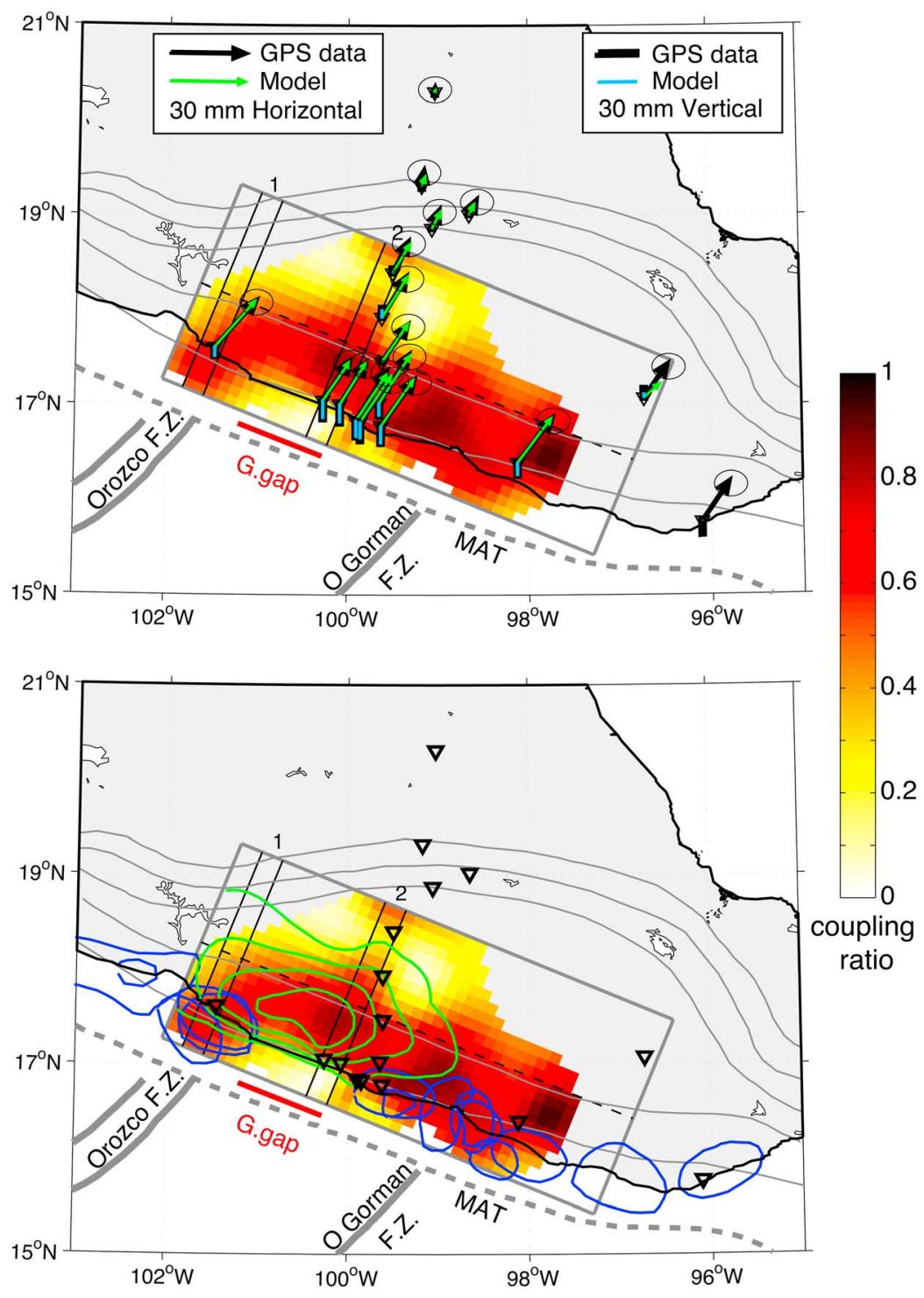

Figure 7. Inter-SSE coupling ratio (geometry B). Areas with insufficient resolution (restitution index $<0.85$, Figure S8) are not represented. (top) Comparison between the observed and modeled inter-SSE displacement (over one year). (bottom) Comparison of the coupling ratio with rupture areas of large earthquakes (blue contours, see Figure 1 for details), and with the location of the SSEs (green contours). The SSEs contours represent the cumulative slip during the last three SSEs. Contour lines have $10 \mathrm{~cm}$ of slip spacing, the smaller one corresponding to $10 \mathrm{~cm}$. Thin black lines, location of the crosssections in Figure 8. Thin dashed black lines, changes in dip of the model subduction plane. Black triangles, GPS station locations. Thick dashed gray line, Middle American Trench (MAT). Thick continuous gray lines, fracture zones. The location of the northwest Guerrero gap (G.Gap) is shown in red.

presumably seismogenic segment of the interplate contact $(-40 \mathrm{~km}$ to $10 \mathrm{~km}$ from the coast) reveals discrepancies between the Guerrero gap region, where the coupling is very low $(<0.2)$ (see Figure 8, cross-section 1), and the western end of the gap, below station ZIHP, where the shallow coupling is $>0.5$ (Figure 8, cross-section 2). This significant shallow coupling in the western part of the gap is only constrained by one station, but appears to be in agreement with the location of relatively frequent large subduction thrust earthquakes. The rupture zones of these recent large earthquakes west of the Guerrero gap (the 1943 M7.7, 1979 M7.6, 1985 M7.6 Petelan earthquakes, and partially the M 8.1
Michoachan earthquake [Nishenko and Singh, 1987; Ortiz et al., 2000]), coincide with the region of significant shallow coupling. The SSE slip contours in Figure 7 show that the SSEs occur in a region of high coupling ratio during the inter-SSE period, and our results do not reveal a strongly locked subduction interface updip of the area where the SSEs occur in the region of the Guerrero gap.

[20] To better constrain the lateral variations in the interSSE coupling, we show in Figure S10 the results of some forwards models (FMs) parameterized with homogeneous along-strike and dip-dependent coupling coefficients. In the first forward model (FM1), the selected coupling coefficients 


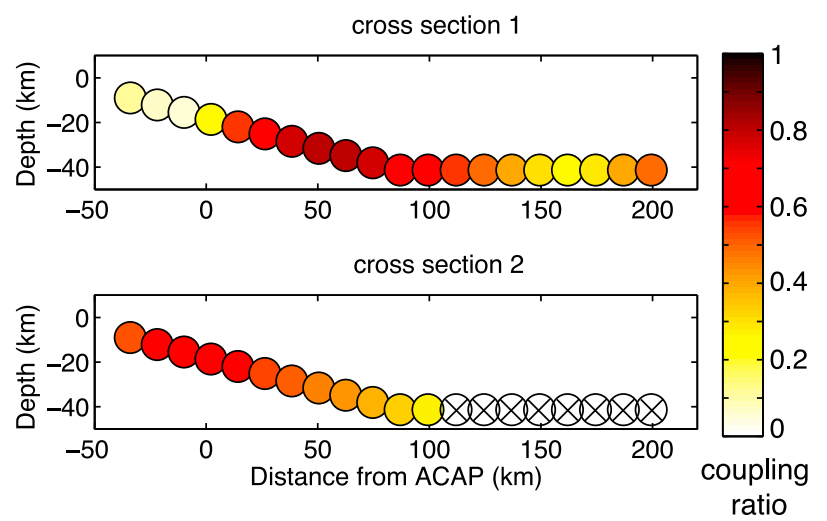

Figure 8. Cross-section of the coupling on the interface, along the two lines shown in Figure 7. Cross-section 1 is located in the Guerrero gap, similar to the cross-sections in Figure 6 , and cross-section 2 is located below the ZIHP station, west of the Guerrero gap. The crossed white dots represent subfaults with insufficient resolution (restitution index $<0.85$, Figure S6).

correspond to the cross-section 1 in Figure 8. The residuals are small for most of the stations, and thus the data do not require along-strike variations in the inter-SSE coupling for the majority of the fault plane. The only station with significant residual is the station ZIHP. In the second forward model (FM2), the coupling coefficients correspond to the cross-section 2 in Figure 8, in which the shallow coupling is high $(>0.6)$. The residuals are large for all coastal stations, except for ZIHP, and show that the model overestimates the northeastward horizontal displacements, and underestimates the negative vertical displacements. FM2 shows that the inter-SSE displacements for the coastal stations located in the Guerrero gap and on the east side of the gap cannot be fitted if the coupling is high on the shallow portion of the interface.
[21] Most previous studies of coupling on the Guerrero gap during inter-SSE periods have suggested low coupling (or no coupling) on the shallow subduction interface (from the trench to the coast; see Kostoglodov et al. [2003], Franco et al. [2005], and Vergnolle et al. [2010] for twodimensional models and Larson et al. [2004] and Iglesias et al. [2004] for three-dimensional inversion). Our results are in agreement with these studies, and suggest that the updip limit of the coupled zone might be deeper in the Guerrero gap than on both sides of the gap, where the contours of large earthquakes suggest a shallower limit of the coupled, seismogenic zone. Our analysis is also consistent with previous studies, which showed a highly coupled interface in the region of transient slip in the inter-SSE period [Larson et al., 2004; Yoshioka et al., 2004].

[22] As the SSEs occurred on a strongly coupled region of the subduction interface, this suggests that they contribute to the stress release in the Guerrero gap. In the next section, we evaluate the amount of slip released by the SSEs in the Guerrero gap, to provide an idea of the long-term (over tens of years) slip deficit accumulation in this region.

\section{Slip Budget}

[23] We compared the slip deficit rates to the slip released during the SSEs, over a period of $12 \mathrm{yr}$, which corresponds to three cycles of SSEs (from 1998.5 to 2010.5). All of the slip values are projected onto the subduction interface for a rake of $100^{\circ}$, which corresponds to the direction of plate convergence. The slip deficit accumulated over a period of $12 \mathrm{yr}$ considering the occurrence of SSEs, is estimated by the summation of the slow-slip for the three SSEs and the inter-SSE slip deficit for 12 yr (Figure 9). In the Guerrero gap, the slip deficit is on average $10 \mathrm{~cm}$ for $12 \mathrm{yr}, 4$ times smaller than on each side of the gap, where the average slip deficit is $\sim 40 \mathrm{~cm}$ for the same period of time. The rupture

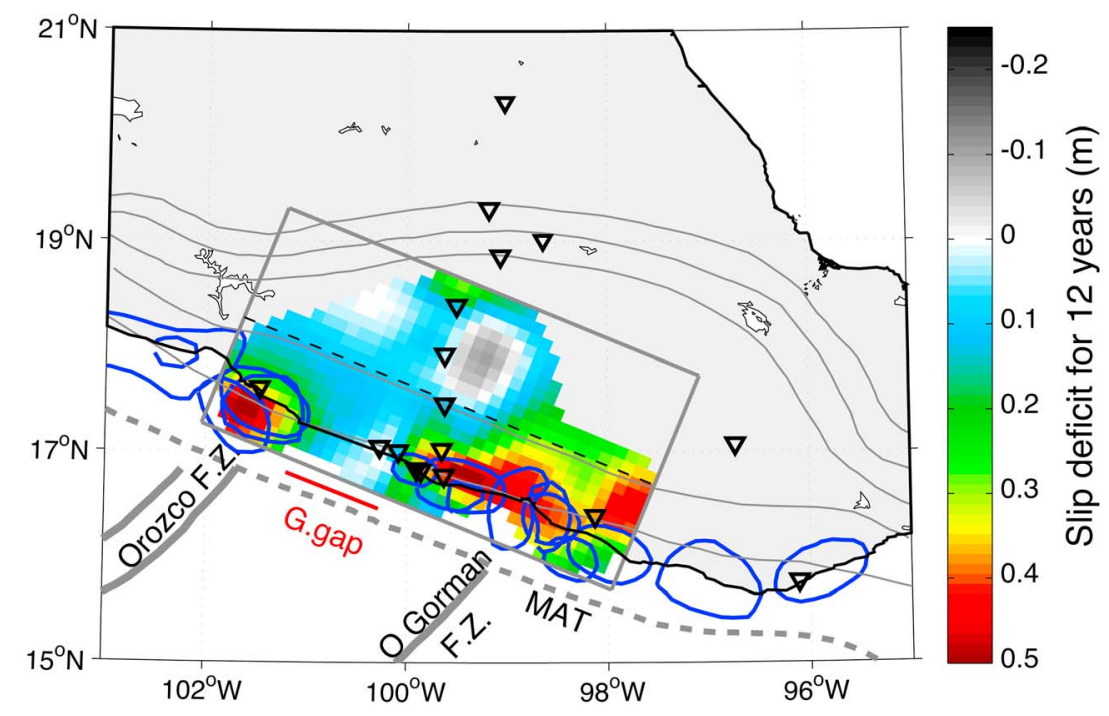

Figure 9. Slip deficit over $12 \mathrm{yr}$ (geometry B). Slip contours of the major earthquakes are in blue. The slip deficit in the Guerrero gap is in average $1 / 4$ of the slip deficit on both sides of the gap. Black triangles, GPS station locations. Thick dashed gray line, Middle American Trench (MAT). Thick continuous gray lines, fracture zones. The location of the northwest Guerrero gap (G.Gap) is shown in red. 
areas of the most recent large earthquakes in the last century coincide with the areas of significant slip deficit.

[24] About $100 \mathrm{~km}-150 \mathrm{~km}$ landward from the coast, the slip deficit appears to be negative (i.e. the SSEs released more strain than was accumulated over the $12 \mathrm{yr}$ period) on either side of the GPS stations profile normal to the coastline. This is likely to be an artifact coming from the linear distribution of the GPS stations, which tends to concentrate the slip in the inversion of the inter-SSE displacements below that line (see Figure 7). The slip deficit is thus probably overestimated just below the line of GPS stations, and underestimated on both sides. This does not affect the results, because our conclusions focus on the lateral variations of the slip deficit below the coast, where our inversions are well resolved (see Figure S8).

[25] The displacement rates inferred from the slip deficit distribution proposed in Figure 9 are shown as dashed lines in Figure 2 (see also Figures S1 and S2 for east and vertical components). The model reproduces the average displacements of the GPS time series. This confirms that our approach of inverting different parts of the signal separately and summing the results, produces a solution that fits the original data. The stations located in the center of the Guerrero gap (CAYA and COYU; Figure 2; red dashed lines) have smaller displacement rates than stations on either side of the gap (Figure 2; blue dashed lines). The largest observed displacement rate is for station ZIHP. This result is consistent with the idea of less slip deficit in the gap than on both sides of the gap.

[26] We can thus conclude here that the occurrence of SSEs in the gap area significantly reduces the accumulation of slip deficit in this region, the slip deficit in the gap being only $1 / 4$ of that outside the gap. The match between the regions of large slip deficit (>40 cm over $12 \mathrm{yr}$ ) and the slip contours of large thrust earthquakes suggests that the Guerrero area is a seismic gap because most, but not all, of the interplate strain is released in SSEs. The next large earthquake in the gap will thus probably be delayed compared to the recurrence time of earthquakes on each side of the gap.

[27] The large, deep slip deficit in the eastern part of the modeled subduction interface (at $98^{\circ} \mathrm{W}$ ) might be because we did not include the SSEs beneath the Oaxaca region in our calculations. These SSEs occurred around $17^{\circ} \mathrm{N}$, and between $96^{\circ} \mathrm{W}$ and $98^{\circ} \mathrm{W}$ [Brudzinski et al., 2007; CorreaMora et al., 2008, 2009], and they might release some elastic strain energy in this region.

\section{Discussion}

\subsection{Extension of the Guerrero SSEs and Conditions for Slow-Slip}

[28] The observation of three SSEs that occurred in the same area gives some insight into the characteristics of these events. The SSEs show similarities in the slip distribution, with a maximum slip on the subduction interface of $\sim 15 \mathrm{~cm}$ in the Guerrero gap region, although their lateral extents are seen to vary. Whichever the SSE, the slow slip also appears to be shallower in the Guerrero gap than on its sides. A recent study of Song et al. [2009] revealed an ultra-slow seismic velocity layer at the top of the subducting plate. SSEs occur only in areas where this ultra-slow velocity layer is present. This ultra-slow velocity layer might represent a high pore fluid pressure zone, that promotes the occurrence of the SSEs under adequate pressure and temperature conditions. Slow-slip phenomena may indeed result from shear slip on faults near failure, with low confining pressure [Peng and Gomberg, 2010].

\subsection{Seismic Behavior of the Guerrero Gap}

[29] Our results reveal the importance of SSEs in the evaluation of elastic strain accumulation in the Guerrero subduction segment of the Middle American Trench. Over the $12 \mathrm{yr}$ of the study, which covers three cycles of SSEs, it appears that the slip deficit in the Guerrero gap is only $1 / 4$ of the slip deficit on both sides of the gap. In the inter-SSE periods, the coupling is almost similar in the Guerrero gap and on its sides, which means that between SSEs, the slip deficit accumulation is almost homogeneous all over the Guerrero subduction segment. This suggests that $3 / 4$ of the strain accumulated during the inter-SSE periods is released aseismically in the Guerrero gap, during the SSEs. Our results are similar for the two plate interface geometries tested. The moment deficit rate in the gap, which was obtained by integrating the annual slip deficit over the northwestern Guerrero gap (from the trench to a depth of $40 \mathrm{~km}$ ) is $6 * 10^{18} \mathrm{Nm} / \mathrm{yr}$. If the elastic strain accumulation observed over the last 12 years was maintained over the last century, the moment strain accumulated since the last earthquake in 1911 is about $6 * 10^{20} \mathrm{Nm}$, which corresponds to a moment magnitude of $M_{w} 7.8$.

[30] Our modeling has limited resolution, in particular due to the low density of the GPS stations, their distribution along two profiles, and the large distances between the subduction interface and the recording stations at the surface. Thus, we cannot detect small variations in the coupling ratios, or small heterogeneities in the slip distributions during the SSEs. Instead, we image the average behaviors on the subduction interface.

[31] The release of the remaining slip deficit in the Guerrero gap might be achieved by different mechanisms. One hypothesis is that the observed slip deficit in the gap is in reality heterogeneous, with areas which remain locked during the interseismic periods, and areas which slip aseismically during transients. The locked patches, which would be too small to be detected by our network, might rupture into thrust earthquakes. They might also explain the variation in the size of the SSEs from one event to another. Our results however appear to rule out the existence of a very large asperity in the Guerrero gap. From several observations of SSEs worldwide, Schwartz and Rokosky [2007] also suggested the existence of transitions from seismic to aseismic frictional behavior within the seismogenic zone, with velocity weakening behavior embedded within regions with velocity strengthening behavior. These mixed-mode fault slip behavior highlights the complexity of defining the seismogenic zone [Marone and Richardson, 2010].

[32] Another alternative is that the subduction interface in the Guerrero gap is conditionally stable. The frictional behavior might thus depend on the slip rate [Noda and Lapusta, 2011] which implies that the Guerrero gap can rupture either seismically or aseismically when one of the neighboring segments rupture. 


\subsection{Comparison Between SSEs in Guerrero and SSEs in Other Subduction Margins}

[33] The SSEs observed in the Guerrero subduction zone are among the largest observed in the world, with equivalent moment magnitudes of 7.4 to 7.6, and durations from 6 months to over one year. In this, they are similar to the long-term SSEs observed in Japan (Tokai and BungoChannel [Hirose and Obara, 2005; Miyazaki et al., 2006]) and in New Zealand (Hikurangi subduction margin [Wallace and Beavan, 2010]). In the Mexican subduction zone, SSEs have also been identified in the Oaxaca segment [Brudzinski et al., 2007; Correa-Mora et al., 2008, 2009], located southeast of the Guerrero segment. In this region, SSEs are smaller than in the Guerrero gap, and they are clearly located downdip of the seismogenic zone, which ruptured in a large $M_{w} 7.6$ thrust earthquake in 1978 .

[34] In the Guerrero gap, the lack of recent large thrust earthquakes and the low interseismic coupling in the gap (revealed by the small slip deficit over the $12 \mathrm{yr}$ of this study) makes it difficult to define a clear seismogenic zone. Thus, we cannot evaluate the location of the SSEs with respect to the seismogenic zone. It is however clear that the SSEs are relatively shallow, as they occur at depths of around $15 \mathrm{~km}$ to $20 \mathrm{~km}$, and down to $40 \mathrm{~km}$. This is similar to long-term SSEs in Bungo Channel (Japan), which occur at shallower depths than short-term SSEs [Hirose and Obara, 2005]. The opposite appears to be true on the Hikurangi subduction margin (New Zealand), where short-durations SSEs occur at shallower depths than long-durations SSEs, although not in the same region of the subduction zone [Wallace and Beavan, 2010]. SSEs in the Hikurangi subduction margin occur in a portion of the subduction interface where the inter-SSE coupling is high $(\sim 0.7)$, which is similar to our observations in the Guerrero gap. Wallace and Beavan [2010] suggested that the SSEs recover nearly all of the elastic strain that accumulates from inter-SSE coupling on the interface in the SSE source regions, and thus the long-term interseismic coupling in the regions where SSEs occur is very low. The same is observed in the Guerrero gap.

\section{Conclusion}

[35] We analyzed $12 \mathrm{yr}$ of continuous GPS records for the Guerrero segment of the Mexican subduction zone. Consistent modeling of the three major SSEs that occurred in this time period was carried out, as well as modeling of the interSSE coupling. Our results show that SSEs account for a major portion of the overall moment release budget in the northwest Guerrero gap. The average slip deficit accumulated in the Guerrero gap during the $12 \mathrm{yr}$ of the present study is only $1 / 4$ of the slip deficit that accumulated on both sides of the gap over the same period of time. Moreover, the regions of large slip deficit match the rupture areas of recent large earthquakes. Limitations in accurately resolving the interSSE coupling and the SSEs locations with GPS time series make us cautious about the interpretation of these results. It is likely that our limited dataset is sufficient only to resolve the first-order lateral variations in the slip distribution of the Guerrero subduction zone. There might be some smaller scale heterogeneities in the degree of coupling and frictional properties in the Guerrero gap that we are not able to resolve.
Such heterogeneous interfaces are likely to produce complex stress accumulations, and irregular earthquakes.

[36] Acknowledgments. The GPS network maintenance and data acquisition were supported by Mexico's PAPIIT IN102105, IN103808 and CONACYT 84544 grants. We are grateful to all of the people who participated in the GPS network installation and maintenance, and in particular to Jose Antonio Santiago. This study is supported by the French National Research Agency (Agence Nationale de la Recherche, ANR G-GAP RA0000C069). Fabrice Cotton and Michel Campillo benefited from Institut Universitaire de France support. We thank Michel Bouchon and other G-Gap participants (I. Manighetti, N. Shapiro, D. Rivet, D. Zigone) for their support and their stimulating discussions.

\section{References}

Brudzinski, M., E. Cabral-Cano, F. Correa-Mora, C. DeMets, and B. Márquez-Azúa (2007), Slow slip transients along the Oaxaca subduction segment from 1993 to 2007, Geophys. J. Int., 171, 523-538, doi:10.1111/j.1365-246X.2007.03542.x.

Correa-Mora, F., C. DeMets, E. Cabral-Cano, B. Marquez-Azua, and O. Diaz-Molina (2008), Interplate coupling and transient slip along the subduction interface beneath Oaxaca, Mexico, Geophys. J. Int., 175, 269-290, doi:10.1111/j.1365-246X.2008.03910.x.

Correa-Mora, F., C. DeMets, E. Cabral-Cano, O. Diaz-Molina, and B. Marquez-Azua (2009), Transient deformation in southern Mexico in 2006 and 2007: Evidence for distinct deep-slip patches beneath Guerrero and Oaxaca, Geochem. Geophys. Geosyst., 10, Q02S12, doi:10.1029 2008GC002211.

Cotte, N., A. Walpersdorf, V. Kostoglodov, M. Vergnolle, J. Santiago, I. Manighetti, and M. Campillo (2009), Anticipating the next large silent earthquake in Mexico, Eos Trans. AGU, 90(21), 181-182.

DeMets, C., R. Gordon, D. Argus, and S. Stein (1994), Effect of recent revisions to the geomagnetic reversal time scale on estimates of current plate motions, Geophys. Res. Lett., 21(20), 2191-2194.

DeMets, C., R. G. Gordon, and D. F. Argus (2010), Geologically current plate motions, Geophys. J. Int., 181, 1-80, doi:10.1111/j.1365-246X. 2009.04491.x

Figueroa, J. (1970), Catálogo de sismos ocurridos en la república mexicana, Univ. Nac. Autón. de México, Mexico City.

Franco, S., V. Kostoglodov, K. Larson, V. Manea, M. Manea, and J. Santiago (2005), Propagation of the 2001-2002 silent earthquake and interplate coupling in the Oaxaca subduction zone, Mexico, Earth Planets Space, 57, 973-985.

Heki, K., S. Miyazaki, and H. Tsuji (1997), Silent fault slip following an interplate thrust earthquake at the Japan Trench, Nature, 386, 595-598.

Hernandez, B., N. Shapiro, S. Singh, J. Pacheco, F. Cotton, M. Campillo, A. Iglesias, V. Cruz, J. Gómez, and L. Alcántara (2001), Rupture history of September 30, 1999 intraplate earthquake of Oaxaca, Mexico $(\mathrm{MW}=7.5)$ from inversion of strong-motion data, Geophys. Res. Lett., 28(2), 363-366.

Herring, T., R. King, and S. McClusky (2006), Introduction to GAMIT/ GLOBK, release 10.3, Dep. of Earth, Atmos. and Planet. Sci., Mass. Inst. of Technol., Cambridge, Mass

Hirose, H., and K. Obara (2005), Repeating short-and long-term slow slip events with deep tremor activity around the Bungo channel region, southwest Japan, Earth Planets Space, 57, 961-972.

Hsu, Y.-J., M. Simons, J.-P. Avouac, J. Galetzka, K. Sieh, M. Chlieh, D. Natawidjaja, L. Prawirodirdjo, and Y. Bock (2006), Frictional afterslip following the 2005 Nias-Simeulue earthquake, Sumatra, Science, 312, 1921-1926, doi:10.1126/science.1126960.

Iglesias, A., S. Singh, A. Lowry, M. Santoyo, V. Kostoglodov, K. Larson, and S. Franco-Sánchez (2004), The silent earthquake of 2002 in the Guerrero seismic gap, Mexico ( $\mathrm{Mw}=7.6)$ : Inversion of slip on the plate interface and some implications, Geofis. Int., 43(3), 309-317.

Kim, Y., R. W. Clayton, and J. M. Jackson (2010), Geometry and seismic properties of the subducting Cocos plate in central Mexico, J. Geophys. Res., 115, B06310, doi:10.1029/2009JB006942.

Kostoglodov, V., W. Bandy, J. Dominguez, and M. Mena (1996), Gravity and seismicity over the Guerrero seismic gap, Mexico, Geophys. Res. Lett., 23(23), 3385-3388.

Kostoglodov, V., S. Singh, J. Santiago, S. Franco, K. Larson, A. Lowry, and R. Bilham (2003), A large silent earthquake in the Guerrero seismic gap, Mexico, Geophys. Res. Lett., 30(15), 1807, doi:10.1029/2003GL017219.

LaBonte, A. L., K. M. Brown, and Y. Fialko (2009), Hydrologic detection and finite element modeling of a slow slip event in the Costa Rica prism toe, J. Geophys. Res., 114, B00A02, doi:10.1029/2008JB005806. 
Larson, K., A. Lowry, V. Kostoglodov, W. Hutton, O. Sánchez, K. Hudnut, and G. Suárez (2004), Crustal deformation measurements in Guerrero, Mexico, J. Geophys. Res., 109, B04409, doi:10.1029/2003JB002843.

Larson, K., V. Kostoglodov, S. Miyazaki, and J.-A. Santiago (2007), The 2006 aseismic slow slip event in Guerrero, Mexico: New results from GPS, Geophys. Res. Lett., 34, L13309, doi:10.1029/2007GL029912.

Manea, V., M. Manea, V. Kostoglodov, C. Currie, and G. Sewell (2004), Thermal structure, coupling and metamorphism in the Mexican subduction zone beneath Guerrero, Geophys. J. Int., 158, 775-784, doi:10.1111/j.1365-246X.2004.02325.x.

Marone, C., and E. Richardson (2010), Learning to read fault-slip behavior from fault-zone structure, Geology, 38, 767-768, doi:10.1130/focus082010.1.

Miyazaki, S., P. Segall, J. McGuire, T. Kato, and Y. Hatanaka (2006), Spatial and temporal evolution of stress and slip rate during the 2000 Tokai slow earthquake, J. Geophys. Res., 111, B03409, doi:10.1029/ 2004JB003426.

Nishenko, S., and S. Singh (1987), Conditional probabilities for the recurrence of large and great interplate earthquakes along the Mexican subduction zone, Bull. Seismol. Soc. Am., 77(6), 2095-2114.

Noda, H., and N. Lapusta (2011), Rich fault behavior due to combined effect of rate strengthening friction at low slip rich fault behavior due to combined effect of rate strengthening friction at low slip rates and coseismic weakening: Implications for chi-chi and tohoku earthquakes, Abstract T42C-03 presented at 2011 Fall Meeting, AGU, San Francisco, Calif., 5-9 Dec.

Ortiz, M., S. Singh, V. Kostoglodov, and J. Pacheco (2000), Source areas of the Acapulco-San Marcos, Mexico earthquakes of 1962 (M 7.1; 7.0) and 1957 (M 7.7), as constrained by tsunami and uplift records, Geofis. Int., 39(4), 337-348.

Pacheco, J. F., and S. K. Singh (2010), Seismicity and state of stress in Guerrero segment of the Mexican subduction zone, J. Geophys. Res., 115, B01303, doi:10.1029/2009JB006453.

Pardo, M., and G. Suarez (1995), Shape of the subducted Rivera and Cocos plates in southern Mexico: Seismic and tectonic implications, J. Geophys. Res., 100(B7), 12,357-12,373.

Peng, Z., and J. Gomberg (2010), An integrated perspective of the continuum between earthquakes and slow-slip phenomena, Nat. Geosci. 3, 599-607, doi:10.1038/ngeo940.

Pérez-Campos, X., Y. Kim, A. Husker, P. Davis, R. Clayton, A. Iglesias, J. Pacheco, S. Singh, V. Manea, and M. Gurnis (2008), Horizontal subduction and truncation of the Cocos Plate beneath central Mexico, Geophys. Res. Lett., 35, L18303, doi:10.1029/2008GL035127.

Perfettini, H., et al. (2010), Seismic and aseismic slip on the central Peru megathrust, Nature, 465, 78-81, doi:10.1038/nature09062.

Radiguet, M., F. Cotton, M. Vergnolle, M. Campillo, B. Valette, V. Kostoglodov, and N. Cotte (2011), Spatial and temporal evolution of a long term slow slip event: The 2006 Guerrero Slow Slip Event, Geophys. J. Int., 184, 816-828, doi:10.1111/j.1365-246X.2010.04866.x.

Sagiya, T. (2004), Interplate coupling in the Kanto district, central Japan, and the Boso Peninsula silent earthquake in May 1996, Pure Appl. Geophys., 161, 2327-2342, doi:10.1007/s00024-004-2566-6.

Savage, J. (1983), A dislocation model of strain accumulation and release at a subduction zone, J. Geophys. Res., 88(B6), 4984-4996.

Schwartz, S., and J. Rokosky (2007), Slow slip events and seismic tremor at circum-Pacific subduction zones, Rev. Geophys., 45, RG3004, doi:10.1029/2006RG000208

Singh, S., and M. Pardo (1993), Geometry of the Benioff zone and state of stress in the overrinding plate in central Mexico, Geophys. Res. Lett, 20(14), 1483-1486.

Song, T., D. Helmberger, M. Brudzinski, R. Clayton, P. Davis, X. PérezCampos, and S. Singh (2009), Subducting slab ultra-slow velocity layer coincident with silent earthquakes in southern Mexico, Science, 324, 502-506, doi:10.1126/science.1167595.

Suárez, G., T. Monfret, G. Wittlinger, and C. David (1990), Geometry of subduction and depth of the seismogenic zone in the Guerrero gap, Mexico, Nature, 345(6273), 336-338.

Tarantola, A. (2005), Inverse Problem Theory and Methods for Model Parameter Estimation, Soc. for Ind. Math., Philadelphia, Pa.

Vergnolle, M., A. Walpersdorf, V. Kostoglodov, P. Tregoning, J. Santiago, N. Cotte, and S. Franco (2010), Slow slip events in Mexico revised from the processing of 11-year GPS observations, J. Geophys. Res., 115, B08403, doi:10.1029/2009JB006852.

Wallace, L. M., and J. Beavan (2010), Diverse slow slip behavior at the Hikurangi subduction margin, New Zealand, J. Geophys. Res., 115, B12402, doi:10.1029/2010JB007717.

Walpersdorf, A., N. Cotte, V. Kostoglodov, M. Vergnolle, M. Radiguet, J. Santiago, and M. Campillo (2011), Two successive slow slip events evidenced in 2009-2010 by a dense GPS network in Guerrero, Mexico, Geophys. Res. Lett., 38, L15307, doi:10.1029/2011GL048124.

Yoshioka, S., T. Mikumo, V. Kostoglodov, K. Larson, A. Lowry, and S. Singh (2004), Interplate coupling and a recent aseismic slow slip event in the Guerrero seismic gap of the Mexican subduction zone, as deduced from GPS data inversion using a Bayesian information criterion, Phys. Earth Planet. Inter., 146, 513-530, doi:10.1016/j.pepi.2004.05.006.

M. Campillo, N. Cotte, F. Cotton, M. Radiguet, and A. Walpersdorf, Institut des Sciences de la Terre, CNRS, Université Joseph Fourier, BP-53, F-38041 Grenoble, France. (mathilde.radiguet@obs.ujf-grenoble.fr) V. Kostoglodov, Instituto de Geofísica, Universidad Nacional Autónoma de Mexico, Ciudad Universitaria, 04510 Mexico City, Mexico.

M. Vergnolle, Géoazur, Observatoire de la Côte d'Azur, CNRS, Université de Nice-Sophia Antipolis, F-06560 Valbonne, France. 